\title{
Adenosquamous Carcinoma of Gallbladder - A Case Report
}

\author{
Nosheen $\mathrm{Nabi}^{1}$, Aamer Mehmood ${ }^{2}$, Naseer Ahmed ${ }^{3}$ \\ ${ }^{1}$ Pathologist, Excel Laboratory, Islamabad \\ ${ }^{2}$ Consultant Pathologist, Excel Laboratory, Islamabad \\ ${ }^{3}$ CEO, Chief Pathologist, Excel Laboratory
}

ABSTRACT

Gallbladder cancer is an uncommon malignancy and majority of these carcinomas are adenocarcinomas. Adenosquamous carcinoma of gallbladder is a rare histopathological subtype of gallbladder carcinoma. It usually presents with symptoms of cholelithiasis like epigastric pain, nausea and bloating. On clinical examination, tenderness is usually present. Radiologically in most of the cases, gallstones are found leading to the diagnosis of cholelithiasis for which cholecystectomy is done. Gallbladder carcinomas are found mostly as an incidental finding on microscopic examination of cholecystectomy specimen. This disease is curable if diagnosed earlier but in most of the cases they present at advanced stages when resection is not possible and prognosis is poor. As this disease is extremely rare so published information is largely based on the case reports and case series. This is a case of 60 years old female patient who underwent cholecystectomy for cholelithiasis with incidental finding of Adenosquamous carcinoma on histopathology report.

Keywords: Adenosquamous, carcinoma, cholelithiasis, Gallbladder.

Correspondence:

Nosheen Nabi

Article info:

Email: Nosheen.Nabi@yahoo.com

Received: July 8, 2021

Accepted: August 31, 2021

Cite this case Report: Nabi N, Mehmood A, Ahmed N. Adenosquamous Carcinoma of

Funding Source: Nil Gallbladder - A Case Report. J Islamabad Med Dental Coll. 2021; 10(3): 186-189. Doi:

Conflict of Interest: Nil

10.35787/jimdc.v10i3.740

\section{Introduction}

Gallbladder carcinoma is an uncommon but lethal malignancy. Adenosquamous carcinoma is a rare neoplasm accounting for $1-12 \%$ of all the gallbladder carcinomas ${ }^{1}$. Only one-third of cases are diagnosed pre operatively while the remaining are diagnosed incidentally on histopathological examination of cholecystectomy specimen ${ }^{2}$. Adenosquamous carcinoma of gallbladder is a locally aggressive neoplasm with poor prognosis ${ }^{3}$. We present a case of 60 years old female patient who underwent cholecystectomy for cholelithiasis with final diagnosis of Adenosquamous carcinoma on histopathology report.

\section{Case Report}

A 60 years old lady presented in a private clinic in a remote area of khyber pakhtunkhwah, Pakistan with complain of epigastric pain. She belongs to a middle class family and her family history for any type of carcinoma was unremarkable. After clinical examination, ultrasound abdomen was suggested which gave the opinion of cholilithiasis as it showed multiple stones in the lumen. Elective cholecystectomy was planned for the cure of cholilithiasis and the specimen was sent for histopathological examination.

On gross examination, gallbladder measured $9 \times 4 \mathrm{~cm}$ and the lumen showed multiple black stones. Two polypoidal nodules were seen in the body of gallbladder, the largest one measured $1.5 \times 1.3 \times 1.3 \mathrm{~cm}$ while smaller one measured $0.8 \times 0.8 \times 0.5 \mathrm{~cm} \quad$ (Figure 1). Microscopoic examination of the large polyp revealed a well differentiated squamous carcinoma and smaller 
polyp showed an adenocarcinoma. The tumor was invading the muscular layer. The margins were free of tumor (Figure 2).

Immunohistochemical stains showed CK7 and CK 20 positivity in adenocarcinoma and $\mathrm{p} 63$ was negative in the polyp containing adenocarcinoma. CDX2 was focally positive (Figure 3)

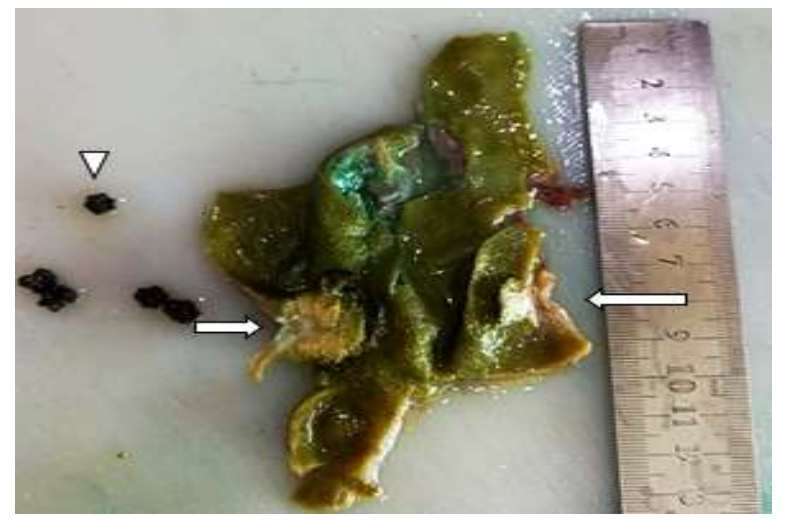

Figure 1: Gallbladder on examination showed one large polyp (small arrow), small polyp (long arrow) and contained multiple small black coloured stones (arrow head). The distance between the two polyps was $2.5 \mathrm{~cm}$.

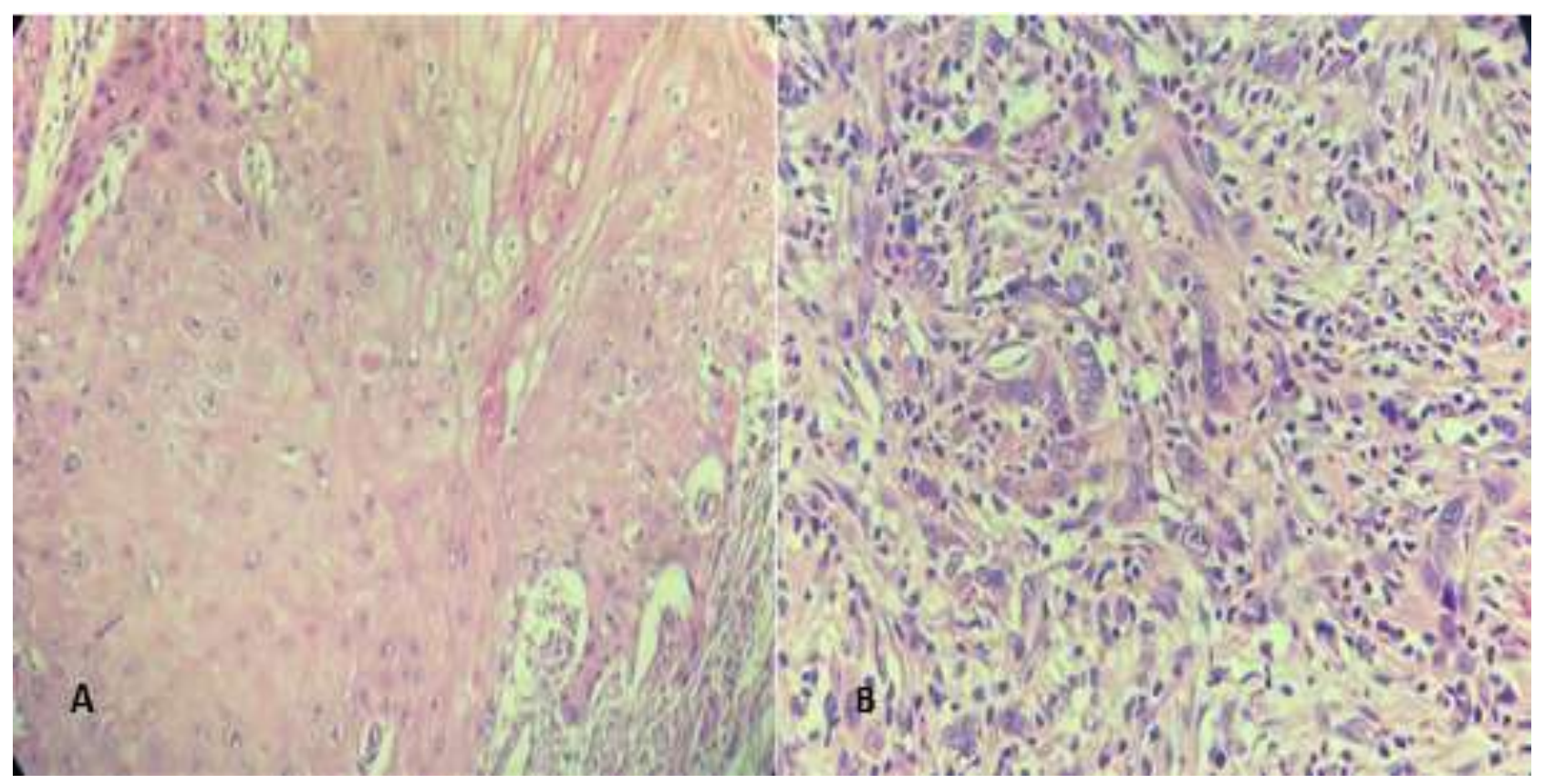

Figure 2: Microscopic examination of the gallbladder showed (A) Squamous cell carcinoma in the larger polyp. (B) Adenocarcinoma in the smaller polyp (H\&E X40). 

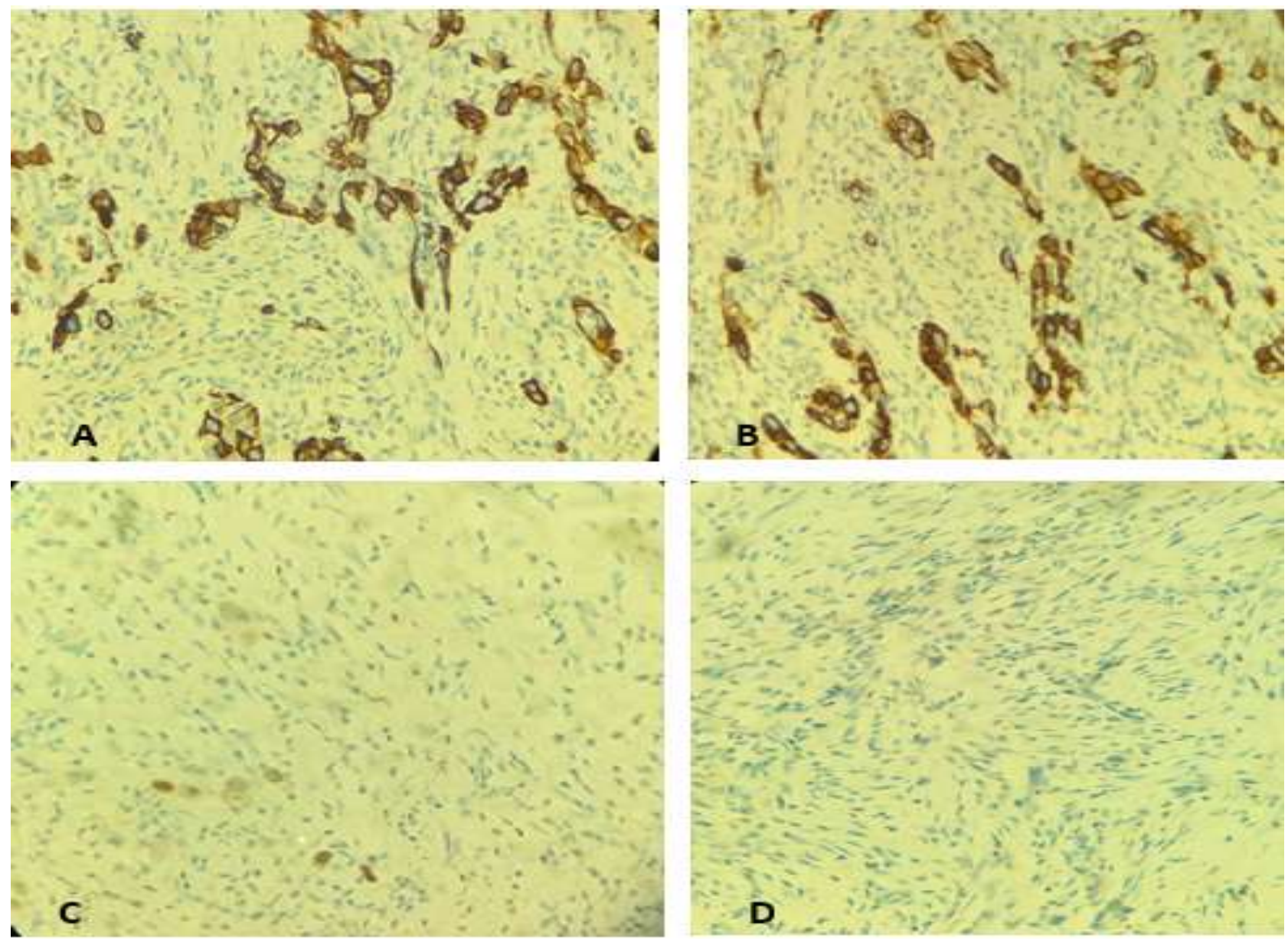

Figure 3: A, B, CK7 and CK 20 immunohistochemical stains are positive in the neoplastic cells, C, p63 is negative in the polyp containing adenocarcinoma while CDX2 is focally positive in the polyp containing adenocarcinoma (40x magnification).

\section{Discussion}

Gallbladder carcinoma is an aggressive malignancy with poor outcome ${ }^{4}$. It is the most common cancer of biliary tract and $5^{\text {th }}$ most common malignancy of gastrointestinal tract ${ }^{5}$. Its increased incidence is seen in India, Pakistan, East Asia, Eastern Europe, South America, Chile and Columbia ${ }^{6}$. The most common histologic subtype of gallbladder cancer is adenocarcinoma which represents approximately $76-90 \%$ of total gallbladder carcinoma cases. Pure squamous and adenosquamous carcinoma constitutes $2-10 \%$ of cases and papillary tumors constitute $5-6 \%$ of cases 7 . Adenosquamous carcinoma of the gallbladder is composed of both glandular and squamous components. If the squamous part is $25 \%-99 \%$ of the tumor, then it is called as adenosquamous carcinoma ${ }^{8}$. Literature on adenosquamous carcinoma is limited because of its rarity. Juan C Rao conducted a large cohort study on 606 cases of gallbladder adenocarcinoma in which squamous cell carcinomas constituted $1 \%$ of the total cases and 4\% were adenosquamous carcinomas. In early stages (Tis-T1a), cholecystectomy alone can cure the disease and for T2-T3, liver resection and lymphadenectomy is indicated ${ }^{10}$. Prognosis of Adenosquamous carcinoma is worse than conventional adenocarcinoma of gallbladder because of early direct invasion of adjacent organs such as liver and duodenum etc. Survival rate is approximately $16 \%$ 
and most of the patients succumb to disease within 6-7 months of diagnosis ${ }^{11}$.

Adenosquamous carcinoma of gallbladder is a rare entity which presents like cholilithiasis. Its behavior is more aggressive than adenocarcinoma of gallbladder and it is locally more invasive.

Because of its rarity, limited literature is available about its clinicopathological behavior and treatment options. Such case reports can provide more detailed information and insight for further research.

There were certain limitations regarding this case as we could not follow up the patient for further treatment and prognosis.

\section{References}

1. Kendre $\mathrm{P}$, Kataria $\mathrm{P}$, Patel A, Mittal L, Mule T. Metastasis as initial presentation of squamous cell carcinoma of gallbladder: A rare clinical entity. Indian Journal of Pathology and Microbiology. 2017 Jul 1;60(3):440.

2. Utsumi $M$, Aoki $H$, Kunitomo $T$, Mushiake $Y$, Yasuhara I, Arata T, et al. Evaluation of surgical treatment for incidental gallbladder carcinoma diagnosed during or after laparoscopic cholecystectomy: single center results. BMC research notes. 2017 Dec;10(1):1-5.

3. Shariff $\mathrm{MH}$, Bhat SP, HL KP. An unusual presentation of adenosquamous carcinoma of gallbladder. Internet Journal of Pathology and Laboratory Medicine. 2016 Dec 22;2(1).
4. Bacalbasa N, Balescu I, Dima S, Popescu I. Surgical Advances in the Treatment of Gallbladder Carcinoma at Different Stages. In Bile Duct Cancer 2019 Sep 25. IntechOpen.

5. Prasad N, Sen S. Gall bladder carcinoma: the facts and the mimics. Egyptian Journal of Radiology and Nuclear Medicine. 2021 Dec;52(1):1-9.

6. Gulwani HV, Gupta S, Kaur S. Squamous cell and adenosquamous carcinoma of gall bladder: a clinicopathological study of 8 cases isolated in 94 cancers. Indian journal of surgical oncology. 2017 Dec;8(4):560-6.

7. Samuel $S$, Mukherjee $S$, Ammannagari N, Pokuri VK, Kuvshinoff B, Groman A, et al. Clinicopathological characteristics and outcomes of rare histologic subtypes of gallbladder cancer over two decades: A population-based study. PLoS One. 2018 Jun 11;13(6):e0198809.

8. Majeed NK, Younes IE, Karimi S, Garzon S. Adenosquamous Carcinoma of the Gallbladder with Sarcomatoid Features. ACG Case Reports Journal. 2020 Sep 1;7(9):e00461.

9. Roa JC, Tapia O, Cakir A, Basturk O, Dursun N, Akdemir $D$, et al. Squamous cell and adenosquamous carcinomas of the gallbladder: clinicopathological analysis of 34 cases identified in 606 carcinomas. Modern Pathology. 2011 Aug;24(8):1069-78.

10. Vargas A, Rodarte-Shade M, Lopez-Garnica D. Adenosquamous carcinoma of the gallbladder. Case report and literature review. HPB. 2017 Apr 1;19:S190.

11. Hong Y, Li X, Cao D. Case Report: Trastuzumab Treatment in Adenosquamous Carcinoma of the Extrahepatic Biliary Tract With Her-2 Amplification. Frontiers in oncology. 2021 Feb 25;11:268. 